J. Clin. Chem. Clin. Biochem.

Vol. 16, 1978, pp. 269-277

\title{
Radioimmunoassay for Parathyrin Characterization of Six Different Antigens and Antisera
}

\author{
By Renate Voll, H. Schmidt-Gayk $\left.{ }^{1}\right), J$. Wiedemann,
}

Clin. Chem. Lab., Med. Clinic of the University, Heidelberg, Germany,

M. Hüfner,

Med. Policlinic of the University of Heidelberg, Germany,

R. Bouillon,

Katholieke Universiteit Leuven, Rega Instituut, Lab. Exptl Geneeskunde, Leuven, Belgium,

H. Keutmann,

Massachusetts General Hospital, Boston, USA,

and $R$. Hehrmann,

Medizinische Hochschule Hannover, Germany

(Received July 5/Novembèr 11, 1977)

Summary: We studied six different antisera to bovine or porcine parathyrin (parathyroid hormone, PTH), produced in rabbit, guinea pigs, sheep or goat, two of which are commercially available. These antisera were characterized with regard to species specificity, affinity and their ability to identify patients with primary hyperparathyroidism. In this heterologous radioimmunoassay system in which [ $\left.{ }^{125} \mathrm{I}\right]$ parathyrin is used as a tracer, some cross-reactivity of the antisera to the hormone or hormone fragments present in human serum was demonstrated. However, there is some overlap of serum immunoreactive parathyrin in patients with or without primary hyperparathyroidism. The results of this and other studies illustrạte the necessity for a homologous radioimmunoassay for human parathyrin.

Radioimmunoassay für Parathyrin: Charakterisierung von sechs verschiedenen Antigenen und Antiseren

Zusammenfassung: Von sechs verșchiedenen Antișeren, dị z. T. kommerziell erhältlich sind, wurden die Sequenzund Spezies-Spezifität, Affinität und diskr̈iminätorische Fähigkeit (Unterscheidung der Patienten mit primärem Hyperparathyreoidismus von Kontrollpersonen) mit Hilfe von sechs verschiedenen Hormonen bzw. Hormonfragmenten und Serumproben bestimmt. Die Antiseren waren gegen Rinder- oder Schweine-Parathyrin (Parathormon, PTH) in Meerschweinchen, Kaninchen, Schaf oder Ziege erzeugt worden. Rinder-[ ${ }^{125}$ I]Parathyrin diente als Tracer. Dieses heterologe Radioimmunoassay-System wies einige Nachteile auf: Die Kreuzreaktivität der Antiseren zu dem Hormon oder den Hormonfragmenten im Serum des Menschen war unvollständig (Überlappungsbereich Kontrollpersonen mit Patienten). Wir schließen aus unseren Resultaten und aus Berichten der Literatur, daß ein homologer Radioimmunoassay für Pạathyrin des Menschen entwickelt werden sollte.

1) Supported by „Deutsche Forschungsgemeinschaft" (Schm 400/1) 


\section{Introduction}

Human parathyroid hormone (hPTH) ${ }^{2}$ ) is a polypeptide consisting of 84 amino acid residues. While the amino acid sequences of positions 1 to 39 and 44 to 84 have been characterized, there remains disagreement over the nature of some residues (1). The amino acid sequence of parathyrin differs among species, and furthermore, metabolism of this hormone results in the presence of several fragments within the circulation. In man for example, the intact hormone, which has a molecular weight of 9500 , represents only a small fraction of the total immunoreactive parathyrin, whereas carboxyterminal fragments of molecular weights from 45007500 daltons are present in concentrations 7 to 20 times greater than the intact hormone $(3,4)$.

Despite the relative predominance of carboxy-terminal fragments, the total concentration of circulating immunoreactive PTH in man is low, usually less than $1 \mu \mathrm{g} / 1$. Consequently, sequential saturation is employed in most laboratories to produce an assay system of sufficient sensitivity to detect circulating immunoreactive PTH in normal individuals $(5,6,7)$. As most antisera have been produced against bovine parathyrin (bPTH), the iodinated bovine hormone will probably exhibit a higher affinity for pooled antisera than will iodinated hPTH. Several antigens and antisera for the detection of hPTH are presently available commercially $(9,10)$. These substances however, have not been sufficiently characterized with regard to amino acid sequence, species specificity, binding of iodinated bPTH, particularly with respect to iodination damage, affinity, sensitivity for the detection of hPTH in normal individuals, and their ability to identify those patients with primary hyperparathyroidism. Furthermore, prior to this study, the influence of different incubation techniques, specifically equilibrium and sequential saturation or the ability of these antisera to identify patients with primary hyperparathyroidism had not been examined.

\section{Materials and Methods}

\section{Antigens}

1-84 bPTH highly purified, $200 \mu \mathrm{g}$ : Inolex Corporation, Chicago, Illinois, USA;

1-34 bPTH: Cat. No. 337700, 0.4 mg; Beckman Instruments, Palo Alto, Ca., USA;

1-34 hPTH: Beckman Instruments, as above;

1-34 hPTH "Boston": obtained from Dr. Henry Keutmann

and Dr. Mike Rosenblatt, Endocrine Unit, Massachusetts General Hospital, Boston, Ma., USA;

1-34 hPTH "Ciba": distributed by the European-PTH-Study-

Group, c/o Prof. $R$. Ziegler, Dept. Internal Med., Univ. Ulm/ Donau;

53-84 bPTH: obtained from Dr. Henry Keutmann, as above;

2) Abbreviations:

hPTH = human parathyrin, bPTH = bovine parathyrin, pPTH $=$ porcine parathyrin
Antisera

"A VI 2": obtained from Dr. R. Bouillon, Leuven;

"Cal": Cat. No. 869052, lyophilized; lot No. 420056, Calbiochem AG, Loewengraben 14, CH-6000 Luzern 5, Switzerland; "Goat 108" (G 108): obtained by courtesy of Prof. M. Peacock, MRC Mineral Metabolism, Univ. Leeds, England;

"He 478/II" and "He 469/VIII": obtained from Dr. Hesch and Dr. Hehrmann, Med. Hochschule, Karl-Wiechert-Allee 9, D-3000 Hannover 61;

"211/32": lyophilized, Wellcome Research Laboratories, Beckenham, Kent, BR3, 3BS, England;

Tracer

$125_{\text {iodide: }}$ spec. act. $296-555 \mathrm{GBq}(8-15 \mathrm{Ci})^{125} \mathrm{I} / \mathrm{mg} \mathrm{I}$, Cat. No. J 5006, Farbwerke Hoechst AG, D-6000 Frankfurt/Main; Whatman CF 1 Cellulose: Fa. Hormuth und Vetter, D-6908 Wiesloch; Sephadex G 50: Pharmacia GmbH, Freiburg/Breisgau; Chloramine $T$, sodium metabisulfite and other substances were obtained "pro analysi" by Fa. Merck AG, D-6100 Darmstadt; Rapid charcoal dispenser: Dosierpumpe Fe 213 , B. Braun, D-3580 Melsungen;

Refrigerated centrifuge: Hettich Roto Silenta K; Fa. Hettich, D-7200 Tuttlingen;

Microtiter plates: No. M 220/24 A; Fa. Greiner, D-7440 Nürtingen;

\section{Iodination}

125 iodide is diluted with phosphate buffer, $0.5 \mathrm{~mol} / \mathrm{l}, \mathrm{pH} 7.4$, to a concentration of $1 \mathrm{mCi} / 10 \mu \mathrm{l}(=37 \mathrm{kBq} / 10 \mu \mathrm{l}) ; \mathrm{bPTH}$ highly purified (Inolex) is diluted in phosphate buffer 0.06 $\mathrm{mol} / \mathrm{l}, \mathrm{pH} 7.4$ to $2 \mu \mathrm{g} / 10 \mu \mathrm{l}$;

Chloramine $\mathrm{T}$ is dissolved to $10 \mathrm{mg} / 10 \mathrm{ml}$ in phosphate buffer $0.06 \mathrm{~mol} / 1, \mathrm{pH} 7.4$;

Sodium metabisulfite: $25 \mathrm{mg} / 10 \mathrm{ml}$ in phosphate buffer, $0.06 \mathrm{~mol} / 1, \mathrm{pH} 7.4$;

$10 \mu \mathrm{l}^{125}$ iodide is added to $10 \mu \mathrm{l} \mathrm{bPTH}$ and the solution is placed in an ice-water bath for $2 \mathrm{~min}$. $10 \mu \mathrm{l}$ of icecold chloramine $T$ is then added, followed after exactly $15 \mathrm{~s}$, by $50 \mu$ of sodium metabisulfite. The solution is immediately transferred to a $3 \mathrm{~cm}$ Pasteur capillary column (CF 1) and eluted with $2 \times 1 \mathrm{ml}$ of phosphate buffer, $0.06 \mathrm{~mol} / 1, \mathrm{pH} 7.4$. The eluate containing free iodide is discarded. $2 \times 1 \mathrm{ml}$ of hypoparathyroid serum are pipetted onto the column and fractions containing 10 drops each are collected. 3-4 fractions containing the radioactive peak are pooled and about $1 / 4$ is placed on a Sephadex G 50 column $(100 \times 1.6 \mathrm{~cm})$; this column is eluted with $\mathrm{pH} 3.0$ buffer containing $9 \mathrm{~g} / 1 \mathrm{NaCl}, 1 \mathrm{~g} / 1$ human serum albumin, $50 \mathrm{mg} / \mathrm{l}$ merthiolate; dextran blue is used as marker for the void volume. Fractions containing $4 \mathrm{ml}$ are collected and counted.

\section{Radioim munoassay}

$35 \mu$ of standard consisting of peptide (as indicated) in hypoparathyroid serum or $35 \mu \mathrm{l}$ of patient or control sera are taken up by a diluter and transferred to a microtiter plate. The diluter adds $100 \mu \mathrm{l}$ of phosphate buffer, $0.06 \mathrm{~mol} / \mathrm{l}, \mathrm{pH} \mathrm{7.4,} \mathrm{containing}$ $1 \mathrm{~g} / \mathrm{l}$ human serum albumin, to determine nonspecific binding (= UB, blank) or $100 \mu \mathrm{l}$ of this buffer containing the antiserum mentioned. The microtiter plates are incubated $48 \mathrm{~h}$ at $4^{\circ} \mathrm{C}$. Tracer $(10,000 \mathrm{cpm}=350 \mathrm{~Bq}, 20 \mu \mathrm{l}$, spec. act. about $150 \mathrm{Ci} / \mathrm{g}$ $=5.6 \mathrm{TBq} / \mathrm{g}$ ) is then added by a Hamilton repeating dispenser. After an additional $48 \mathrm{~h}$ at $4^{\circ} \mathrm{C}, 100 \mu \mathrm{l}$ of charcoal $(50 \mathrm{~g} / \mathrm{l}$ Norit $\mathrm{A}$ in phosphate buffer as above) is added by a rapid charcoal dispenser. The plates are incubated for $1 \mathrm{~h}$ at $4^{\circ} \mathrm{C}$ and centrifuged $10 \mathrm{~min} \times 4000 \mathrm{rpm}(\mathrm{r}=17 \mathrm{~cm}) ; 200 \mu \mathrm{l}$ of the supernatant are trañsferred to counting vials and counted for $5 \mathrm{~min}$.

\section{Results}

The titers of the antisera were determined by serial. dilution (12). The dilution, at which $1000 \mathrm{cpm}(=35 \mathrm{~Bq})$ are bound specifically, are shown in table 1 : 
Tab. 1. Antiserum code; species immunized and injected antigens are indicated. Working titer represents the dilution at which $1000 \mathrm{cpm}$ are specifically bound.

\begin{tabular}{|c|c|c|c|}
\hline $\begin{array}{l}\text { antiserum } \\
\text { code }\end{array}$ & $\begin{array}{l}\text { working } \\
\text { titer }\end{array}$ & $\begin{array}{l}\text { species } \\
\text { immunized }\end{array}$ & antigen injected \\
\hline A VI 2 & $1: 20,000$ & guinea pig & bPTH, booster hPTH \\
\hline Cal & $\begin{array}{l}50 \mathrm{ml} \text { per } \\
\text { vial }\end{array}$ & rabbit & bPTH \\
\hline Goat 108 & $1: 5,000$ & goat & bPTH \\
\hline $\mathrm{He} 478 / \mathrm{II}$ & $1: 4,000$ & sheep & bPTH, booster pPTH \\
\hline He 469/VIII & $1: 10,000$ & sheep & bPTH, booster pPTH \\
\hline $211 / 32$ & $1: 100,000$ & guinea pig & bPTH \\
\hline
\end{tabular}

For the determination of sequence and species specificity, the antisera were first incubated with 1-84 bPTH. The dose-response curves are shown in figure 1 .

As can be seen, all antisera recognize $1-84 \mathrm{bPTH}$. The greatest sensitivity is found with antiserum A VI 2. To determine the aminoterminal sequence specificity of all six antisera, each was incubated separately with four different synthetic aminoterminal fragments: $1-34$ bPTH Beckman, 1-34 hPTH Beckman, 1-34 hPTH Boston and 1-34 hPTH Ciba. Therefore, 9 standard dilutions of each peptide with concentrations from 7.8 to $2000 \mathrm{pmol} / 1$ were produced. Only the antisera

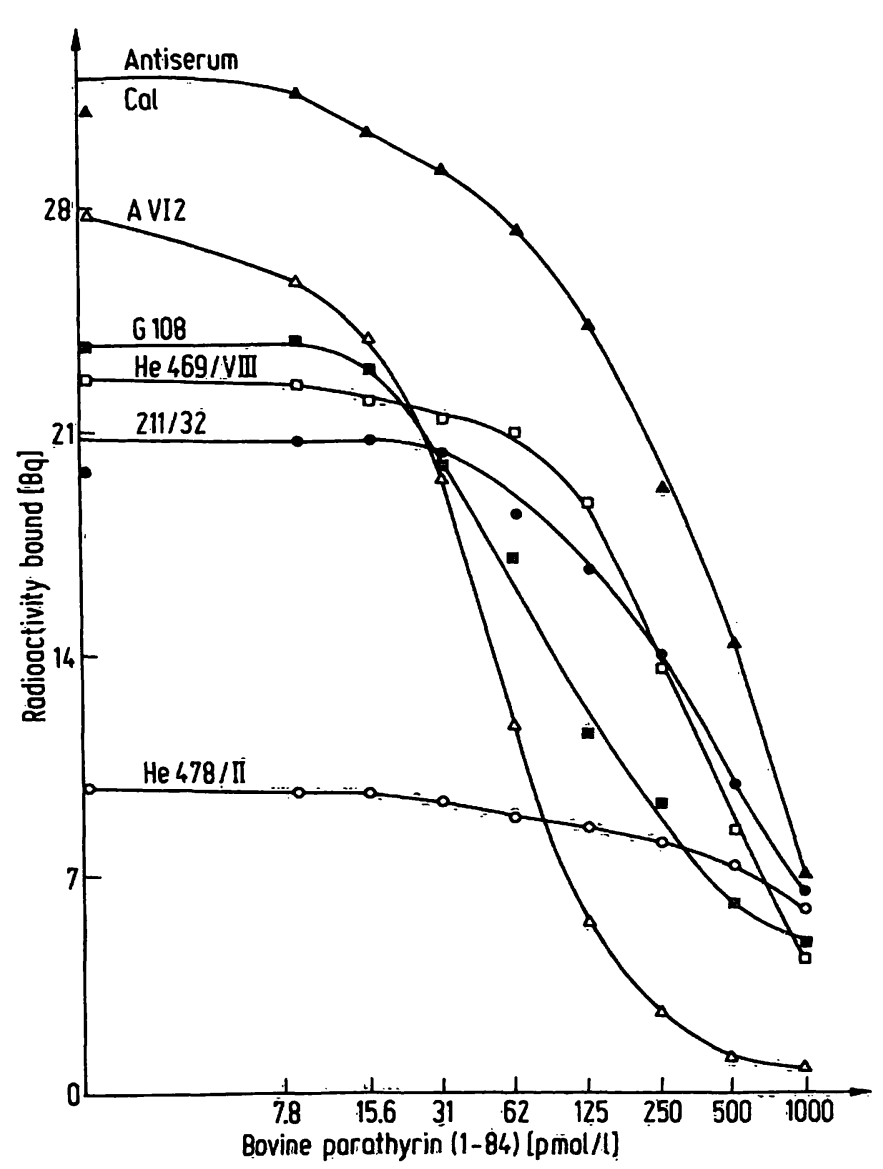

Fig. 1. Incubation of six different antisera with bovine parathy= rin $(1-84)$ for $48 \mathrm{~h}$; thereafter tracer (bovine $\left[{ }^{125} \mathrm{I}\right]$ parathyrin) was added and incubation continued for a further $48 \mathrm{~h}$ (sequential saturation).
He 469/VIII and He 478/II were tested with concentrations as great as $5000 \mathrm{pmol} / 1$.

Antiserum 211/32 reacts with 1-34 hPTH Boston and 1-34 bPTH Beckman, with a decrease of $33 \%$ from standard zero to standard $2000 \mathrm{pmol} / \mathrm{l} .1-34 \mathrm{hPTH}$ Ciba results in a decrease of $15 \%$ from standard zero to standard $2000 \mathrm{pmol} / \mathrm{l}$. No displacement of tracer occurs with 1-34 hPTH Beckman in the dilutions zero $2000 \mathrm{pmol} / \mathrm{l}$. An additional experiment was performed with antiserum $211 / 32$ and greater peptide concentrations ( 0.1 to $50 \mathrm{nmol} / \mathrm{l}) .50 \mathrm{nmol} / 1$ of $1-34 \mathrm{hPTH}$ Boston results in displacement of $60 \%$ of tracer from antiserum $211 / 32$, whereas only $13 \%$ of tracer are displaced by $1-34 \mathrm{hPTH}$ Beckman.

Antiserum Goat 108 reacted only with 1-34 bPTH; a displacement of only $8 \%$ of the tracer was observed. No other antisera showed any aminoterminal reactivity.

For determination of carboxy-terminal specificity, all antisera were incubated with 53-84 bPTH obtained by one of us (H.K.). The results are given in figure 2.

About $90 \%$ of the tracer is displaced from antiserum A VI 2, 40\% is displaced from antiserum $211 / 32$, and minor amounts from antiserum $\mathrm{Cal}$ and Goat 108.

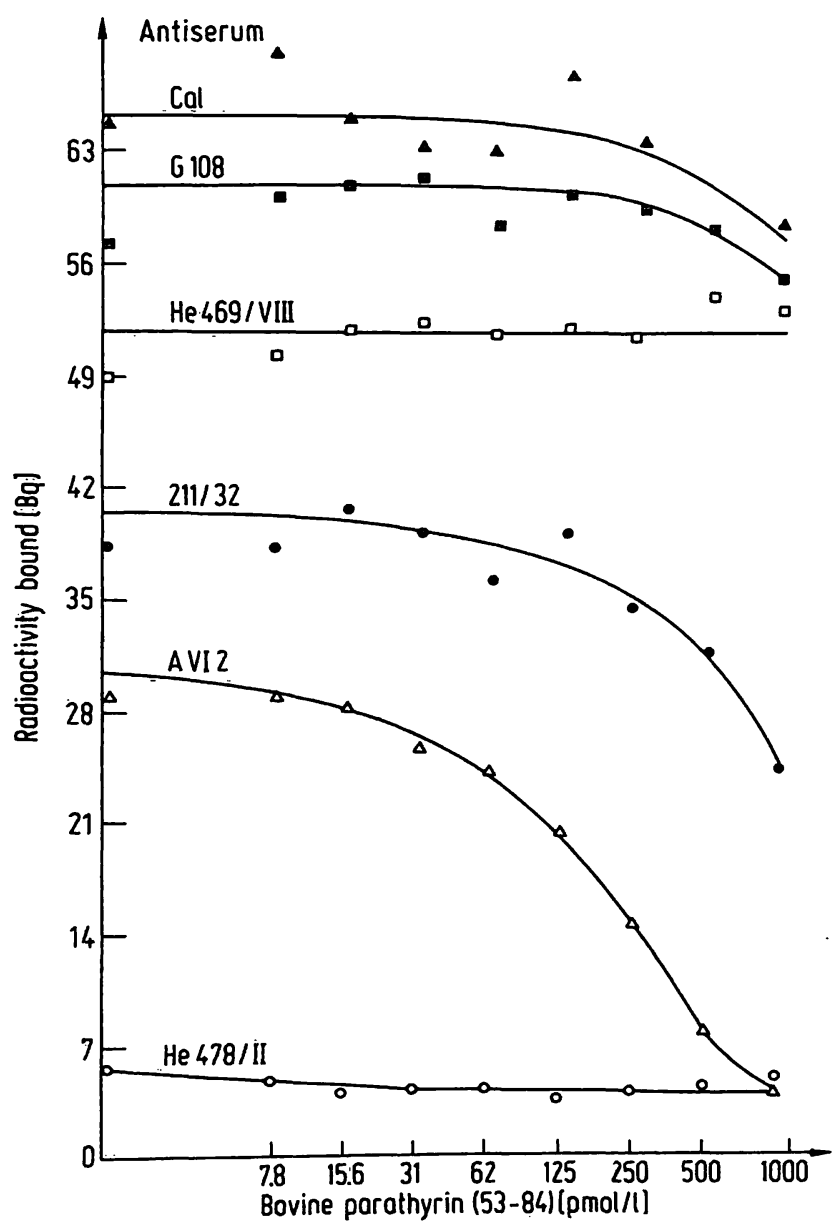

Fig. 2. Incubation of six different antisera with bovine parathyrin (53-84) (sequential saturation). 


\section{Species specificity}

As has been shown in figure 1, all antisera recognize the bovine 1-84 hormone. To determine cross-reactivity of the antisera to hPTH, serum from a patient with severe primary hyperparathyroidism was diluted serially with hypoparathyroid serum. These hPTH serum standard dilutions were incubated for $48 \mathrm{~h}$ with the different antisera. Bovine [ ${ }^{125}$ I]parathyrin was then added and the incubation continued for $48 \mathrm{~h}$. The results are shown in figure 3.

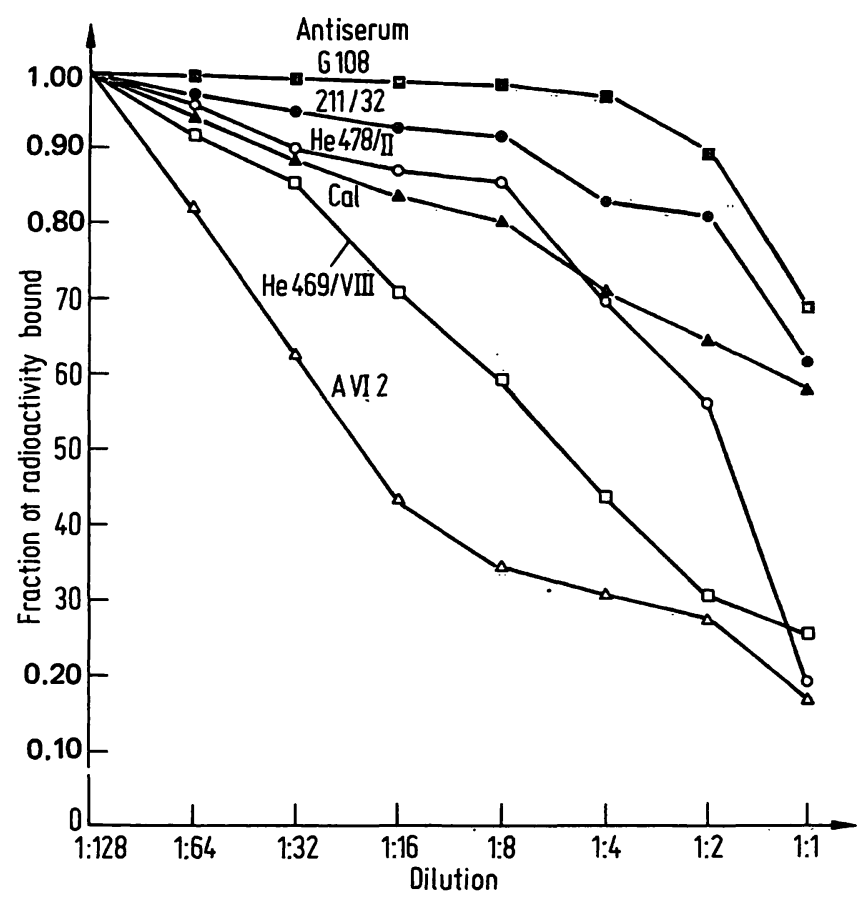

Fig. 3. Cross reactivity of the antisera with human serum parathyrin (-fragments). Serum of a patient with severe primary hyperparathyroidism (serum calcium $4.3 \mathrm{mmol} / \mathrm{l}$ ) was diluted serially with parathyrin-free serum. Sequential saturation.

\section{Binding of iodinated bPTH}

Most investigators use gel-filtration chromatography to separate iodinated hormone from "iodination damage" and free ${ }^{125}$ iodide. It is known that different antisera bind more of the iodinated hormone obtained from the increasing or decreasing part of the hormone peak. The behaviour of the six antisera under study towards the iodinated fractions is shown in figure 4 and 5.

Antiserum Goat 108 not only binds the intact hormone peak, but also "iodination damage". The increasing part of the iodinated hormone peak is bound preferentially by antiserum Goat 108 and He 469/VIII. The increasing and decreasing part is bound equally by antiserum 211 / 32 , A VI 2 and He 478/II. The decreasing part is bound preferentially by antiserum Cal. Unfortunately, in this experiment (fig. 4) antiserum 211/32 was diluted $1: 150,000$ resulting in less than optimal binding (1: 100,000 dilution).

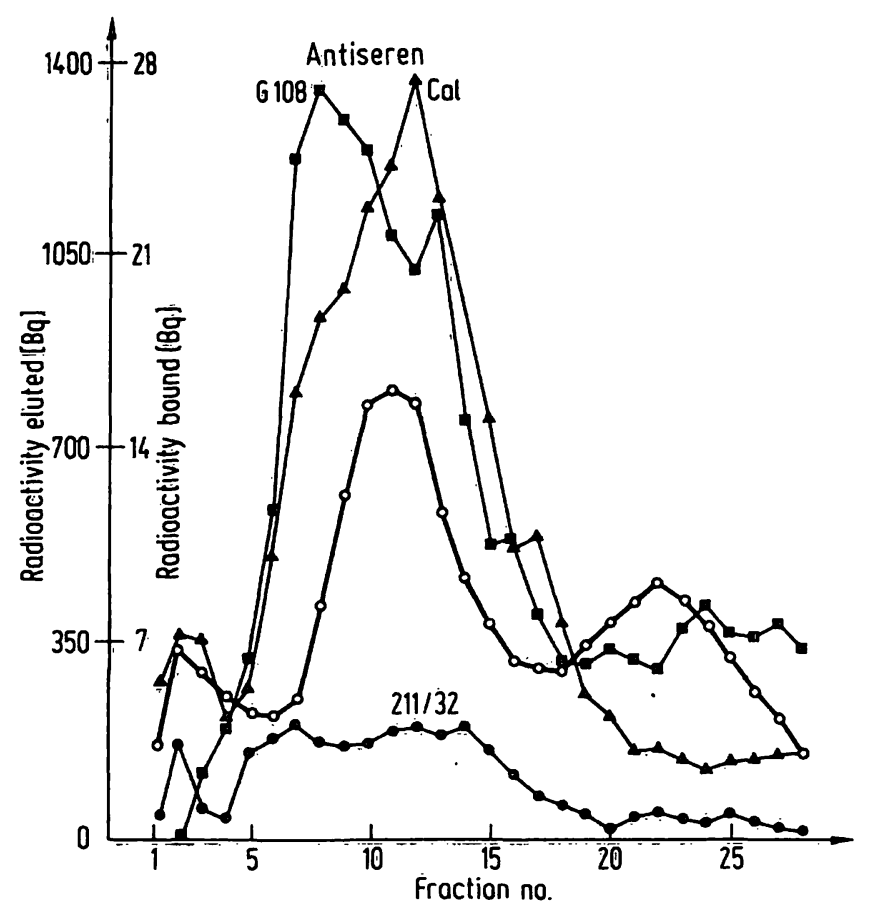

Fig. 4. Gel-filtration on Sephadex G-50 column $(90 \times 1.6 \mathrm{~cm})$ of bovine $\left[{ }^{125} I\right]$ parathyrin $(1-84)$. Dextran-blue was eluted from the column in fractions. $1-3$, bovine [ ${ }^{125}$ I]parathyrin $(1-84)$ in fractions 8-15, and "damage" in fractions 17-28. Each fraction was diluted to $5000 \mathrm{cpm} / 20 \mu \mathrm{l}(=150 \mathrm{~Bq} / 20 \mu \mathrm{l})$ and incubated with antiserum $\mathrm{G} 108, \mathrm{Cal}$ and $211 / 32$ for $48 \mathrm{~h}$ to determine the fractions of highest binding activity.

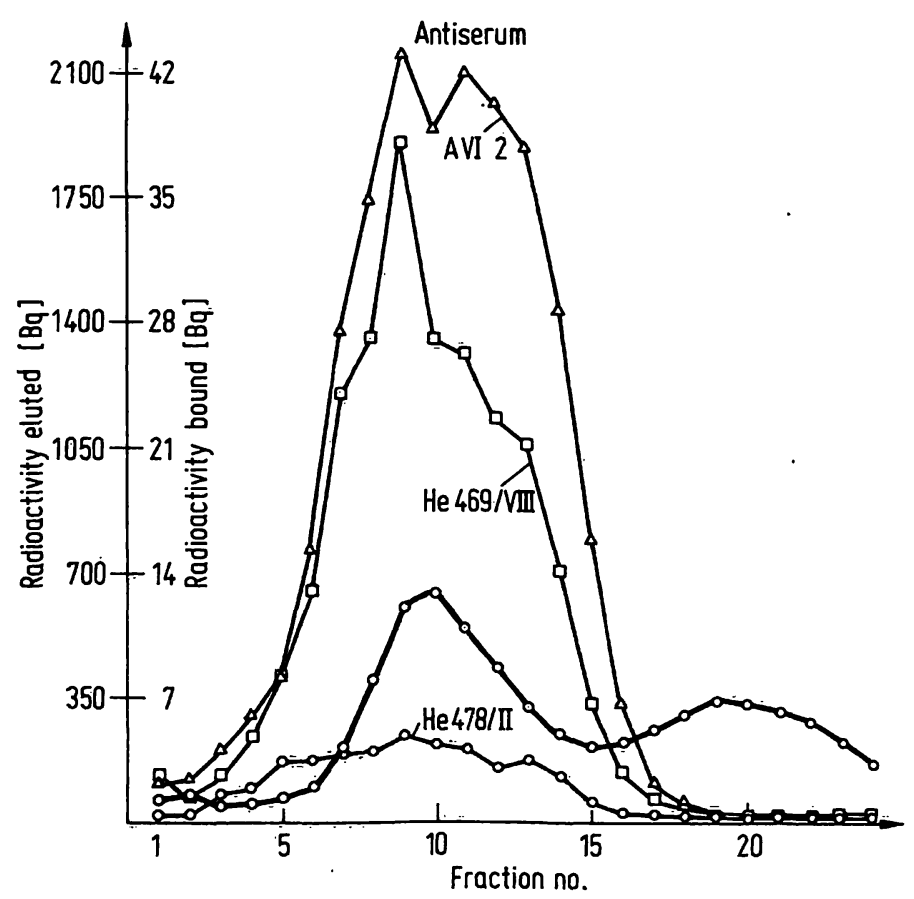

Fig. 5. Gel-filtration of bovine $\left[{ }^{125} I\right]$ parathyrin $(1-84)$ on Sephadex G-50 column. Conditions as described in fig. 4. Incubation with antisera A VI 2, He 469/VIII and $\mathrm{He} 478 / \mathrm{II}$.

As can be seen in figure 4; antiserum Goat 108 binds the iodinated hormone very well. Because hPTH is not recognized by this antiserum, we subsequently used it 
for "excess antibody" experiments in which the iodinated hormone peak obtained from the Sephadex G 50 column is tested for maximal binding (determination of tracer quality).

bPTH unfortunately becomes structurally altered during iodination with chloramine T. Only $0.80-0.95$ of the "iodinated hormone" peak obtained from gel-filtration is bound when antiserum Goat 108 is added in excess (dilution $1: 20$ ).

\section{Affinity}

The affinity of the six antisera for bovine [ $\left.{ }^{125} \mathrm{I}\right]$ parathyrin was studied according to Scatchard (13). For this purpose, a serial dilution of bovine $\left[{ }^{125} \mathrm{I}\right]$ parathyrin was incubated with the antisera for $48 \mathrm{~h}$. Graphical evaluation according to Zettner (5) is shown in figure 6.

The Scatchard analysis shown in Figure 6 was calcuated with regard to a maximal binding fraction of 0.80 (antiserum Goat 108 in excess, diluted $1: 20$, bound only 0.80 of the iodinated hormone). Antisera A VI 2 and $\mathrm{Cal}$ displayed a higher bound/free ratio than the other antisera. Antisera Goat 108 and $\mathrm{He}$ 478/II (results not shown) had a bound/free ratio lower than $\mathrm{He}$ $469 /$ VIII and $211 / 32$. The affinity constant is equivalent to the negative slope. Because different subpopulations of antisera exist (varying slopes), a linear regression analysis was not performed.

According to the Scatchard plot and sequence analysis, antisera A VI 2 and Cal could be useful for the measurement of carboxy-terminal parathyrin-residues. These results however, give no indication of the clinical usefulness of the antisera. This can only be judged from cross reactivity experiments (Fig. 3 ) and measurement of serum samples obtained from definitive healthy persons and surgically confirmed patients with primary hyperparathyroidism. Measurement of serum samples

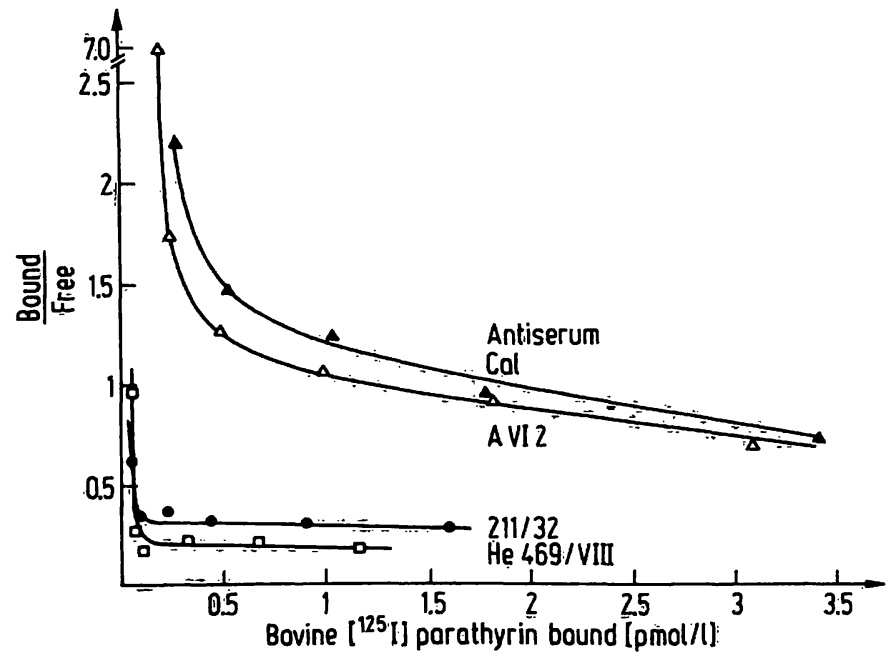

Fig. 6. Affinity of the antisera A VI 2, Cal, He 469/Vĭli and $211 / 32$ plotted according to Scatchard. Results for antisera G108 and He 478/LI not shown. obtained from patients with secondary hyperpara. thyroidism (renal failure) is less suitable for testing the discriminatory power of an antiserum, because in these patients very high parathyrin levels are usually observed and these may be detected even with antisera of medium quality. Therefore, serum parathyrin levels of 30 healthy persons with a normal serum calcium (2.2$2.6 \mathrm{mmol} / \mathrm{l}$ ) and 30 patients with surgically confirmed primary hyperparathyroidism were measured with all antisera except antiserum Goat 108 (poor cross reaction to $\mathrm{hPTH}$ ) and $\mathrm{He} 478 / \mathrm{II}$ (insufficient binding). One patient was excluded because tertiary hyperparathyroidism was misclassified as primary hyperparathyroidism.

The parathyrin concentrations, calculated as $\mathrm{pmol} / \mathrm{l}$ ( $1 \mathrm{pmol} / \mathrm{l}$ is roughly equivalent to $10 \mathrm{ng} / \mathrm{l}$, standard 1-84 bPTH) are plotted as shown for antiserum A VI 2 on figure 7.

In this experiment, circulating parathyrin levels in 16 out of 30 controls were below the limits of detectability of the system. This may be due to use of the tracer three weeks after its iodination. In other experiments, serum parathyrin levels of about $90 \%$ of healthy controls are measurable by antiserum A VI 2.

As is shown in figure 7, the group of patients with primary hyperparathyroidism is well separated from healthy controls. However, by measuring only para-

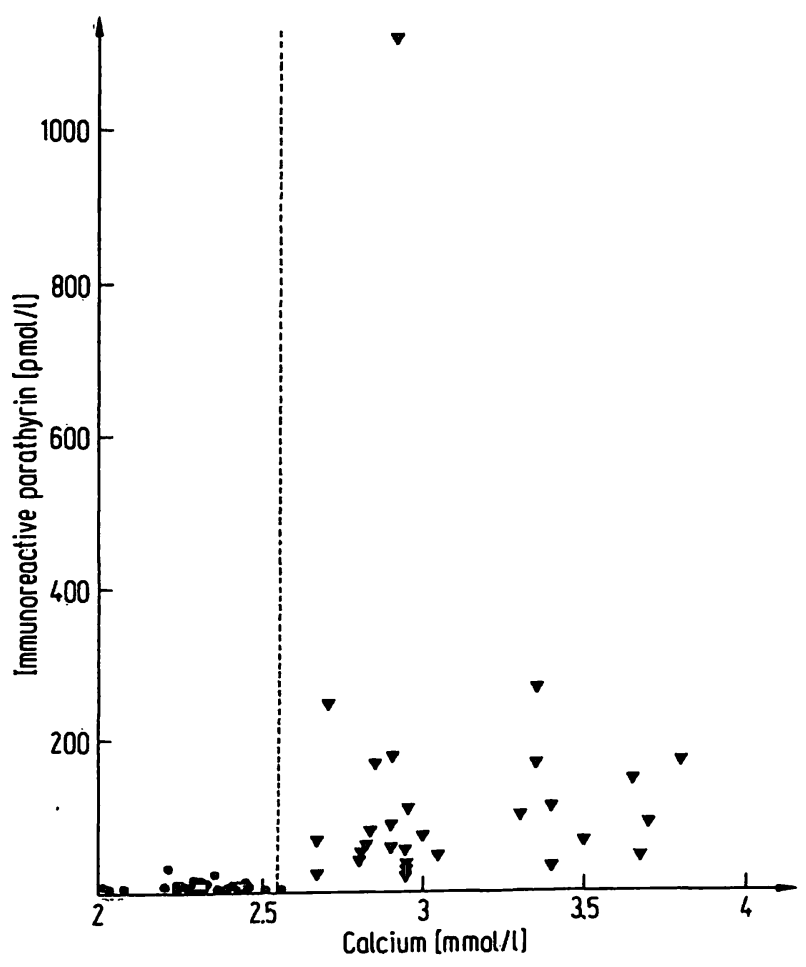

Fig. 7. Serum concentrations of calcium and immunoreactive parathyrin plotted for antiserum A VI 2, Sequential saturation technique. Immunoreactive parathyrin in three patients is in the upper normal range. $\checkmark$ primary hyperparathyroidism - controls 
thyrin, three patients with primary hyperparathyroidism are in the upper normal range. The comparison of parathyrin levels of healthy controls and patients with antiserum $\mathrm{Cal}$ is shown in figure 8 .

The patients with primary hyperparathyroidism are separated from controls on the basis of serum calcium levels. However, this discrimination is not achieved by measuring parathyrin only. As can be seen, a large overlap between controls and patients occurs. In 15 patients with primary hyperparathyroidism, the concentration of parathyrin is in the normal range. In contrast to antiserum A VI 2, parathyrin levels in four patients with primary hyperparathyroidism are too low for measurement.

The parathyrin concentrations obtained by antiserum He 469/VIII in healthy controls and patients with primary hyperparathyroidism are shown in figure 9.

Again, a separation of controls from primary hyperparathyroidism is obtained. 23 out of 29 patients with primary hyperparathyroidism could be distinguished from controls by measuring parathyrin. The circulating parathyrin levels of six patients with primary hyperparathyroidism were too low for measurement.

Parathyrin concentrations in healthy controls and patients with primary hyperparathyroidism as studied with antiserum $211 / 32$ are shown in figure 10.

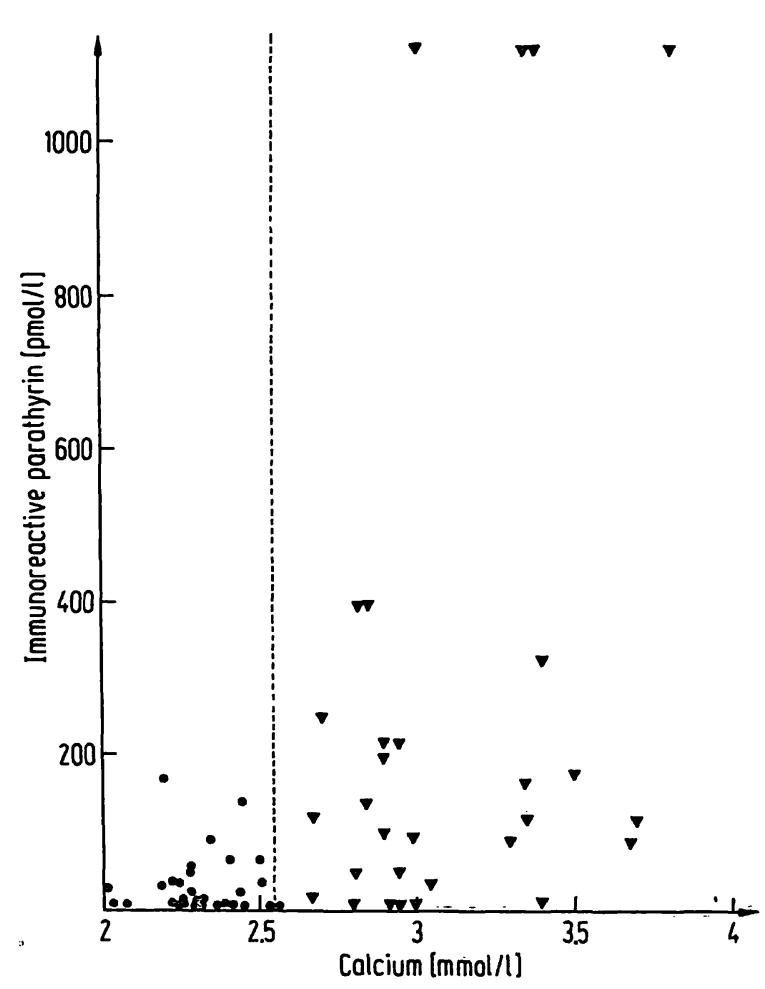

Fig. 8. Serum concentrations of calcium and immunoreactive parathyrin plotted for antiserum Cal. Sequential saturation. Separation is not achieved by measuring immunoreactive parathyrin only.

$\checkmark$ primary hyperparathyroidism

- controls

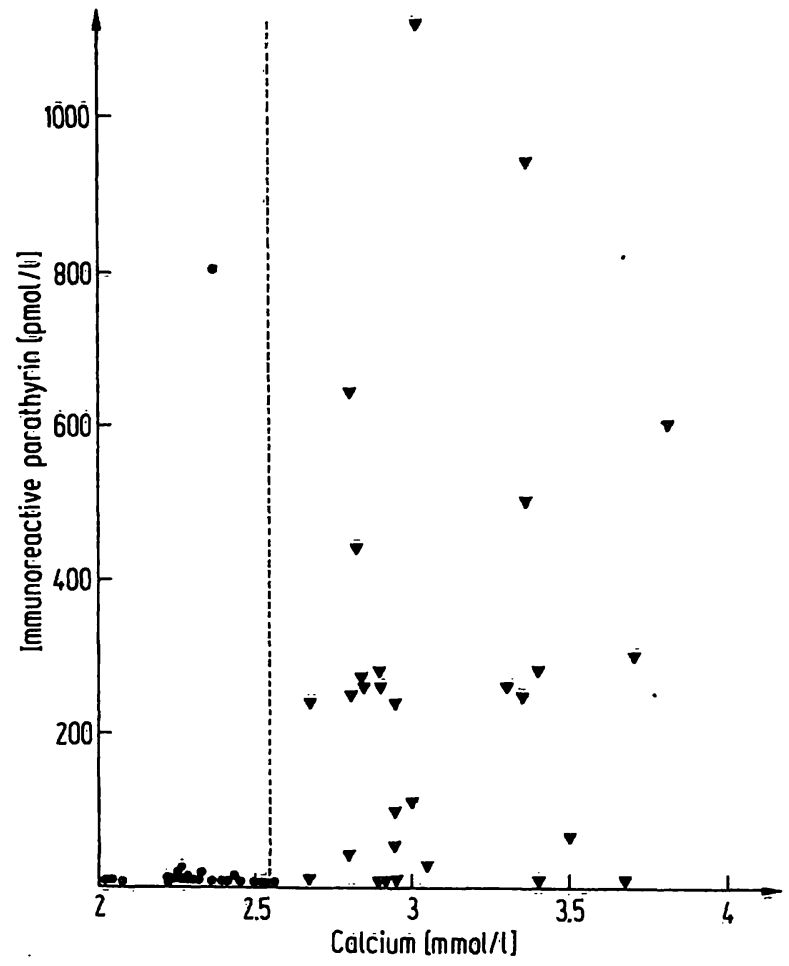

Fig. 9. Serum concentrations of calcium and immunoreactive parathyrin plotted for antiserum He 469/VIII. Sequential sāturation. Separation is achieved by measuring immunoreactive parathyrin in 23 of 29 patients. $\checkmark$ primary hyperparathyroidism

- controls

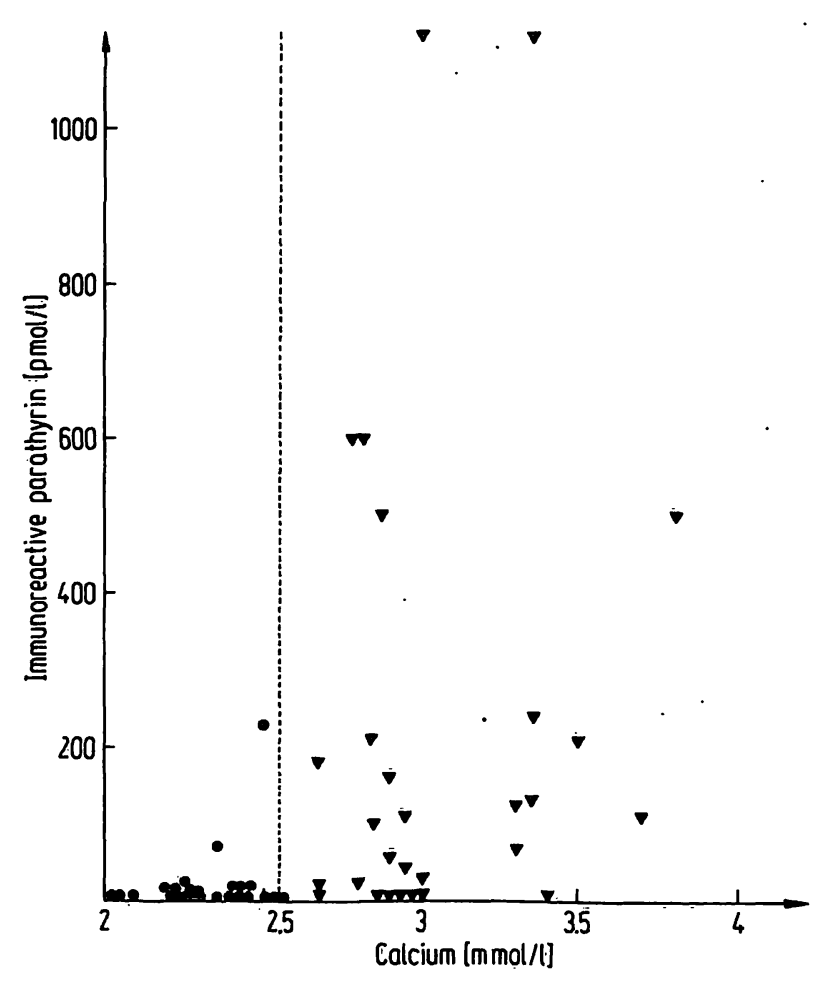

Fig. 10. Serum concentrations of calcium and immunoreactive parathyrin plotted for antiserum 211/32. Sequential saturation technique. Separation is achieved by measuring immunoreactive parathyrin in 22 of 29 patients.

$\checkmark$ primary hyperparathyroidism

- controls 
Again, a separation of controls from primary hyperparathyroidism is obtained. 22 out of 29 patients with primary hyperparathyroidism are distinguished from controls by measuring parathyrin alone. The serum levels of seven patients with primary hyperparathyroidism are too low for measurement.

\section{Equilibrium technique}

During review of the literature, we were impressed by the fact that the only group using equilibrium conditions for the incubation of tracer and standards or unknown samples, respectively, reports a large overlap of controls and patients with primary hyperparathyroidism (14). To our knowledge the influence of equilibrium or sequential saturation on the discriminatory power of antisera has not been determined. Therefore controls and patients with primary hyperparathyroidism were measured with two antisera with the equilibrium and the sequential saturation technique. Under equilibrium conditions the overlap increased: antiserum He 469/VIII detected elevated serum parathyrin concentrations in $80 \%$ (by sequential saturation) and in $63 \%$ (by equilibrium) of patients with primary hyperparathyroidism. Antiserum A VI 2 showed elevated parathyrin concentrations in $90 \%$ of these patients by sequential saturation and in $84 \%$ by equilibrium. Therefore, routine assays for parathyrin should be run under conditions of sequential saturation.

\section{Imprecision}

Some overlap is produced by the imprecision inherent in radioimmunoassay. The ,intra"-assay coefficient of variation (CV) in the steepest part of the standard curve (highest precision) is $6.1 \%(n=22$ triplicates of one serum, mean $249 \mathrm{pmol} / 1$, standard deviation $15.1 \mathrm{pmol} / \mathrm{l}$ ) for antiserum A VI 2. We also determined the "inter"assay CV and the accuracy. The serum of a patient with surgical hypoparathyroidism, who was treated with vitamin $D$ and calcium, was supplemented with 1-84 bPTH to a concentration of $111 \mathrm{pmol} / 1$. This "control serum 111 " was measured in triplicate in 34 different assays ( $=$ a period of 34 weeks). A mean of $123 \mathrm{pmol} / 1$ was obtained with a standard deviation of 15.7 and a CV of $12.7 \%$.

\section{Discussion}

Many antisera used for the radioimmunoassay of parathyrin are poorly characterized with respect to sequence specificity.

\section{Antiserum A VI 2}

This antiserum is regarded as carboxy-terminal in specificity (11). Using A VI 2, Bouillon observed no displacement of bovine $\left[{ }^{125} \mathrm{I}\right]$ parathyrin $1-84$ in experiments with 1-34 bPTḦ. Furthermore, he obtained smaller increases of immunoreactive parathyrin in serum with A VI 2 during EDTA-infusion than with antiserum $211 / 32$. He did not report experiments with $1-34$ $\mathrm{hPTH}$ and 53-84 bPTH. We observe no displacement with 1-34 hPTH and nearly total displacement of tracer with 53-84 bPTH. We therefore conclude that antiserum A VI 2 is entirely carboxy-terminal in specificity. We suggest that there is no reactivity with the medium part of the parathyrin sequence from amino acid residues $35-52$. As is reflected by the steepness of the standard curves, the affinity determined according to Scatchard (13) is high in comparison with the other antisera. This antiserum may be used clinically, as nearly complete separation between controls and patients with primary hyperparathyroidism is achieved by measuring parathyrin in alone (11). We found a high degree of cross reactivity to hPTH or hPTH fragments in serum.

\section{Antiserum Cal}

We used the titer of this antiserum which the manufacturer recommends. Therefore, we achieved more binding with antiserum $\mathrm{Cal}$ than with other antisera. As far as we could determine, no data concerning sequence specificity of this antiserum exist. We observed no displacement of tracer with different 1-34 peptides and a small displacement with 53-84 bPTH. There may exist some reactivity with that part of the parathyrin molecule corresponding to amino acid residues 35-52. However, while affinity according to Scatchard (13) is high in comparison to the other antisera, this antiserum is of restricted clinical use because there is considerable overlap between controls and patients with primary hyperparathyroidism.

\section{Antiserum Goat 108}

This antiserum reacts partly with both the amino- and carboxy-terminal portions of parathyrin. In addition, there may be some reactivity with the portion of the molecule corresponding to amino acid residues 35-52. 1-34 bPTH and 53-84 bPTH are not able to displace bovine $\left[{ }^{125} \mathrm{I}\right]$ parathyrin $1-84$ in amounts comparable to the intact 1-84 bPTH.

Affinity according to Scatchard is low in comparison with A VI 2 and Cal. Goat 108 may be used for purification of tracer according to the method of Schopman (15) or for quality control of the labelled hormone (excess antibody experiments, estimation of maximal binding).

\section{Antiserum He 469/VIII}

This antiserum is regarded as carboxy-terminal in specificity and its clinical usefulness has been demonstrated by Hehrmann et al. (16). However, the number of patients they investigated was small ( 9 patients with primary hyperparathyroidism). In our experiments, we observed no displacement with 1-34 peptides and only 
a small displacement of tracer with 53-84 bPTH. However, this antiserum was elicited against bovine and porcine parathyrin; consequently our results with the bovine fragments may not reflect the sequence specificity. The affinity determined according to Scatchard is lower than the affinity of A VI 2 or Cal, which is reflected in dose-response curves less steep than with A VI 2 or Cal. While the antiserum may be used clinically, slightly increased serum levels of parathyrin are not detected. Perhaps, by increasing the serum volume from $35 \mu$ to 50 or $100 \mu$, better discriminatory power may be achieved. For our radioimmunoassay of parathyrin we chose a serum volume of $35 \mu$, because nonspecific binding with this small volume was low and the same with all serum samples. Due to insufficient binding, no experiments were performed with antiserum $\mathrm{He} 478$ / II with respect to clinical usefulness. In other laboratories, sufficient binding and discrimination between controls and patients has been achieved with a later bleeding (He 478/VI, personal communication).

\section{Antiserum $211 / 32$}

Several experiments have been reported using antiserum $211 / 32$. With $1-34 \mathrm{bPTH}$, more than $50 \%$ of the label is displaced $(9,10,11,17)$. Furthermore it was shown that circulating immunoreactive parathyrin after parathyroidectomy rapidly decreased (half-life of 10-15 min) using $211 / 32(10)$. As we reported earlier, the initial half life of parathyrin in human plasma after removal of parathyroid adenomas was $10-20 \mathrm{~min}$ as measured by the same antiserum. Further results using different 1-34 hPTH peptides have, to our knowledge, not been reported. Woo observed some 10-15\% decrease of binding using the 53-84 fragment of bPTH. In our experiments, $1-34$ bPTH displaces $60 \%$ of labelled $1-84$ $\mathrm{bPTH}$, and the 53-84 bPTH fragment displaces $40 \%$ of the tracer. We conclude that the mid-portion of the parathyrin-molecule is not recognized by this antiserum. $211 / 32$ is mainly directed towards the amino-terminal portion of parathyrin.

The structure of the human 1-34 peptide synthesized by the Boston group is nearly as effective as the bovine $1-34$ in displacing the bovine $\left[{ }^{125} \mathrm{I}\right]$ parathyrin $1-84$. However, the structure synthesized by Ciba or Beckman is less effective. It is premature to conclude which synthetic peptide most resembles that of man. It is suggested that the $1-34 \mathrm{hPTH}$ Boston is more effective because it is more similar to the bovine structure.

The affinity of antiserum 211/32 determined according to Scatchard is lower than the affinity of antiserum A VI 2 or Cal. Antiserum 211/32 may be used clinically because sufficient separation of controls from patients with primary hyperparathyroidism is achieved. An overlap of controls with primary hyperparathyroidism was also reported by Bouillon (11), Kleerekooper (10) and Woo (9). This antiserum is now used by us for locali- zation of parathyroid adenomas by measurement of native parathyrin in samples obtained from venous catheterization of the neck.

\section{Antigens}

Obviously there is no problem in eliciting antisera against the different peptides mentioned. With 1-84 bPTH we were able to produce antisera in each of 15 guinea pigs (unpublished results). Using 1-84 bPTH, Arnaud (6) reported the production of antisera of low cross-reactivity to hPTH in most animals. The antisera reported here, which were produced against bPTH (Cal, Goat 108, 211/32) either could not discriminate patients from controls completely ( $\mathrm{Cal}, 211 / 32)$ or cross-reacted poorly (Goat 108).

The immunoreactivity of the $1-34$ peptides differs markedly from that of the 1-84 peptides. Antisera have been raised successfully against $1-34 \mathrm{hPTH}$ Boston and 1-34 hPTH Ciba (18). One antiserum ("G 127") elicited against 1-34 hPTH Boston reacted less with 1-84 hPTH than with the 1-34 antigen (19). This difference in reactivity might be caused by

a) an error in the sequence of the 1-34 peptide or

b) amino-terminal conformational changes induced by the amino acids $35-84$.

Another antiserum ("G 199"), which was raised against 1-84 bPTH and which reacts mainly with the aminoterminal, did not discriminate between intact $\mathrm{hPTH}$ and 1-34 hPTH Boston, whereas 1-34 hPTH Ciba showed little cross reactivity. Our own results obtained with antiserum 211/32 point to the fact that 1-34 hPTH Boston resembles the bovine structure more closely. This 1-34 peptide was much more effective in displacing the bovine $\left[{ }^{125} I\right]$ parathyrin $1-84$. Our results, like the data reported on antiserum G 199 (19), would support the 1-34 hPTH Boston structure: antiserum 211/32 recognizes the intact human hormone and the 1-34 hPTH Boston.

The small difference of 3 amino acids between 1-34 hPTH Boston and 1-34 hPTH Ciba alters the immunoreactivity drastically, as reported by Visser et al (18). These investigators immunized rabbits against 1-34 hPTH Ciba. The antisera of these animals cross-reacted apparently 100-fold less with 1-34 hPTH Boston or 1-84 hPTH than with 1-34 hPTH Ciba.

The serum from sheep immunized with pPTH (He 469/VIII) does not completely separate patients with primary hyperparathyroidism from controls. The serum of the only animal immunized with hPTH (adenoma extract) discriminates between patients with primary hyperparathyroidism and controls. It has to be noted that our results were obtained from a single serum specimen of patients or controls. In practice, most often two or three samples are analyzed from patients suspected of having primary hyperparathyroidism. As has 
been shown by Almqvist (14), this will improve diagnostic accuracy substantially. More than 100 patients with primary hyperparathyroidism are now diagnosed by means of the radioimmunoassay for parathyrin with antiserum A VI 2 and serum calcium determination.

It is concluded from these results that a radioimmunoassay for hPTH, employing antiserum against hPTH, human $\left[{ }^{125} \mathrm{I}\right]$ parathyrin (or analogs with certain substituted amino acids for better labelling) and hPTH standards, should be developed in the future. This

\section{References}

1. Keutmann, H. T. (1974), in: Clinics in Endocrinology and - Metabolism, (Buckle, R. ed.) W. B. Saunders Co., London, Philadelphia, Toronto, Vol. III, No. 2, 173-197.

2. Arnaud, C. D., Sizemore, G. W., Oldham, S. B., Fischer, J. A., Tsao, H. S. \& Littledike, T. (1971), Am. J. Med. 50, 630638.

3. Habener, J. F., Segre, G. V., Powell, E., Murray, T. M. \& Potts, J. T. jr. (1972), Nature New Biol. 238, 152-154.

4. Canterbury, J. M., Levey, W. S. \& Reiss, E. (1973), J. Clin. Invest. 52, 524-527.

5. Zettner, A. (1973), Clin. Chem. 19/7, 699-705.

6. Arnaud, C. D., Tsao, H. S. \& Littledike, T. (1971), J. Clin. Invest. 50, 21-34.

7. Lequin, R. M., Hackeng, W. H. L. \& Schopman, W. (1970), Acta Endocrinol. Copenhagen 63, 655-666.

8. Pratt, J. J. \& Woldring, M. G. (1976), Clin. Chim. Acta 68, 87-90.

9. Woo, J. \& Singer, F. R. (1974), Clin. Chim. Acta 54, 161168.

10. Kleerekooper, M., Ingham, J. P., MacCarthy, S. W. \& Posen, S. (1974), Clin. Chem. 20, 369-375. could further improve the value of parathyrin determination.

\section{Acknowledgment}

We thank Mrs. Petra Förster and Mr. U. Deuschle for careful technical assistance and Prof. Teitelbaum, The Jewish Hospital of St. Louis, Mo., USA, for correcting the manuscript. In addition we would like to thank Dr. Michael Rosenblatt, Endocrine Unit, Massachusetts General Hospital and Harvard Medical School, Boston, USA, for preparation of 1-34 hPTH.

11. Bouillon, R., Koninckx, P. \& De Moor, P. (1974), in: Radioimmunoassay and related procedures in medicine. International Atomic Energy Agency, Vienna, 1, 353-365.

12. Skelley, D. S., Brown, L. P. \& Besch, P. K. (1973), Clin. Chem. 19, 146-186.

13. Scatchard, G. (1949), Ann. N.Y. Acad. Sci. 51, 660-672.

14. Almqvist, S., Hjern, B. \& Wästhed, B. (1975), Acta Endocrinol. 78, 493-509.

15. Schopman, W., Hackeng, W. H. L. \& Lequin, R. M. (1970), Acta Endocrinol. 63, 643-654.

16. Hehrmann, R., Wilke, R., Nordmeyer, J. P. \& Hesch, R. D. (1976), Dtsch. Med. Wochenschr. 101, 1726-1729.

17. Tanaka, M., Abe, K., Adachi, J., Yamaguchi, K., Miyakawa, S., Hirakawa, H. \& Kumaoka, S. (1975), Endocrinol. Jpn. $22,471-477$.

18. Visser, T. J., Buurman, C. J., Hackeng, W. H. L. \& Birkenhäger, J. C. (1975), J. Endocrinol. 67, 141-142

19. Hendy, G. N., Barling, P. M. \& O'Riordan, J. L. H. (1974), Clin. Sci. Mol. Med. 47, 567-576.

Dr. H. Schmidt-Gayk, Clin. Chem. Lab., Med. Univ. Clinic, Bergheimerstr. 58,

D-6900 Heidelberg 


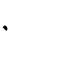

